\title{
Development of a fuzzy ammonia slip detection controller for use with HD SCR DEF dosing strategy
}

\author{
Adnan Shaout ${ }^{*}$ and Yang Yang \\ Electrical and Computer Engineering, University of Michigan-Dearborn, USA
}

Received: 14-February-2017; Revised: 01-April-2017; Accepted: 03-April-2017

(C)2017 ACCENTS

\begin{abstract}
This paper presents a fuzzy logic controller based ammonia detection algorithm to predict and capture ammonia slip for commercial vehicles. The current vehicle emission standard requires a well-designed selective catalytic reduction (SCR) system which must deliver a high efficiency in terms of nitrogen oxides reduction while maintaining a low ammonia slip from the tailpipe. Fuzzy logic was used because of the following: the SCR system is a nonlinear, multiple factor dependent system, and the information causing ammonia slip, for most cases, is not clearly defined. An ammonia sensor installed downstream of the SCR catalyst can be used as a straightforward method for potential ammonia slip detection. However, from the cost efficiency perspective, introducing a smart ammonia sensor would greatly increase the cost of the system. The proposed fuzzy controller system collects information from the existing system sensors then incorporates it into the Matlab/Simulink environment. The paper presented the SCR system architecture, diesel emission fluid (DEF) dosing strategy as well as the detailed algorithm of ammonia slip detection with results and comparison to the conventional method.
\end{abstract}

\section{Keywords}

Vehicle emission standard, Diesel emission fluid dosing system, Fuzzy controller, Matlab/Simulink, Selective catalytic reduction, Heavy duty engines.

\section{Introduction}

As better fuel economy and higher power efficiency provided by diesel engine compared with other energy sources in the field, the diesel-powered vehicles like commercial buses or trucks are still quite popular all over the world. On the other hand, as the side effect comes with diesel, the particulate matter as well as nitrogen oxides from diesel vehicle has drawn the public's attention over the time [1]. As a result, the mandatory standards are getting stricter with commercial vehicle emissions; for instance, environmental protection agency (EPA) sets 0.02 g/bhp.hr of tailpipe NOx for heavy-duty engine in 2015 compared with only $0.20 \mathrm{~g} / \mathrm{bhp}$.hr in 2007.

As shown in Figure 1, a typical architecture of a full after-treatment system for heavy duty (HD) engines includes diesel oxidation catalyst (DOC), diesel particulate filter (DPF) for PM treatment, SCR and downstream ammonia oxidation catalyst ((AOC), often left out for cost saving).

\footnotetext{
*Author for correspondence
}

A $32.5 \%$ urea solution, also known as diesel emission fluid (DEF) is then dosed into the hot exhaust fluid, decomposed into NH3 (ammonia) and water, with the catalytic coating on SCR, it converts NOx into harmless N2 (nitrogen) and water.

Considered as the primary control objective, the correlation between the urea dosing flow rate and NOx reduction efficiency, can be generally interpreted as that the greater the amount of urea delivered for SCR reactions, the better the NOx reduction would be.

However, it is not always the case, typically under transient engine conditions; the unused NH3 will slip from the catalyst as a result of exhaust temperature fluctuation across the SCR catalyst. Hence, NH3 slip detection is required as part of the system control strategy to compensate for urea dosing calculation with the aim of keeping the $\mathrm{NH} 3$ slip under limited level.

As previously mentioned, the most straightforward approach for NH3 slip detection is to utilize an ammonia sensor installed downstream of SCR 
catalyst; it provides $\mathrm{NH} 3$ concentration measurement in real time and transmits the message back to DEF dosing control unit through CAN bus, as illustrated in Figure 2. Other methods, as published in US patent, $2012 / 0085083$ A1, it is a two-NOx-sensor based polynomial coefficient algorithm which analyzes measured signals from two NOx sensors and compared with predicted information from the SCR model to differentiate NH3 slip from poor NOx conversion [4]. Another method, as disclosed in US patent 2014/0123629 A1, it correlates predicted and measured NOx conversion efficiency at time step 2 with information collected at time step 1 to determine whether the ammonia slip exists [5]. However, as is well known in the industry, $\mathrm{NH} 3$ sensor will greatly increase system cost if it was introduced as part of feedback control strategy, which makes it unappealing to most after-treatment system consumers. As for the second approach, a welldeveloped SCR model should be required to provide predicted tailpipe NOx and NH3, which actually put a higher standard on the SCR model itself. As far as the third method, as stated in the patent, the algorithm requires a steady state as entry condition of the proposed algorithm, however, as is observed from most testing datasets, ammonia slip most likely occur during transient conditions, which suggests a robust design shall consider all possible vehicle or engine conditions for the detection algorithm.
A dynamic programming (DP) algorithm that has a tolerable computational load was proposed in [6-8] to simultaneously reduce the tailpipe NOx and ammonia slip. An adaptive sliding-mode observer design problem for SCR system in diesel-engine after treatment systems was proposed [9]. The observer gain tuning method is developed based on the stability analysis of the estimation error system. The proposed observer design method is applied to an SCR system of a medium-duty diesel engine.

In the remainder of this paper, we first discuss the advantage of using a fuzzy logic controller (FCL) for ammonia slip detection (ASD) in section 2. Then we discuss the input selection and the implementation of a fuzzy inference system with Fuzzy Logic Toolbox in section 2 as well. The comparison between traditional timer-based baseline algorithm and fuzzy logic controller has been demonstrated in section 3 with simulation results. The final conclusion is shown in section 4 .

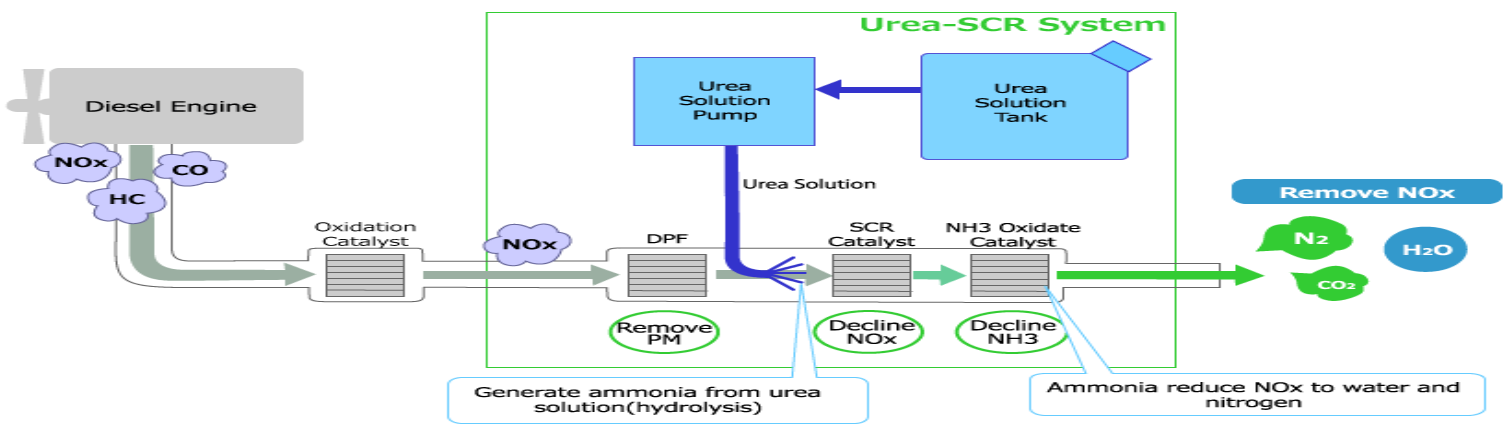

Figure 1 A typical diesel after-treatment system layout [2]

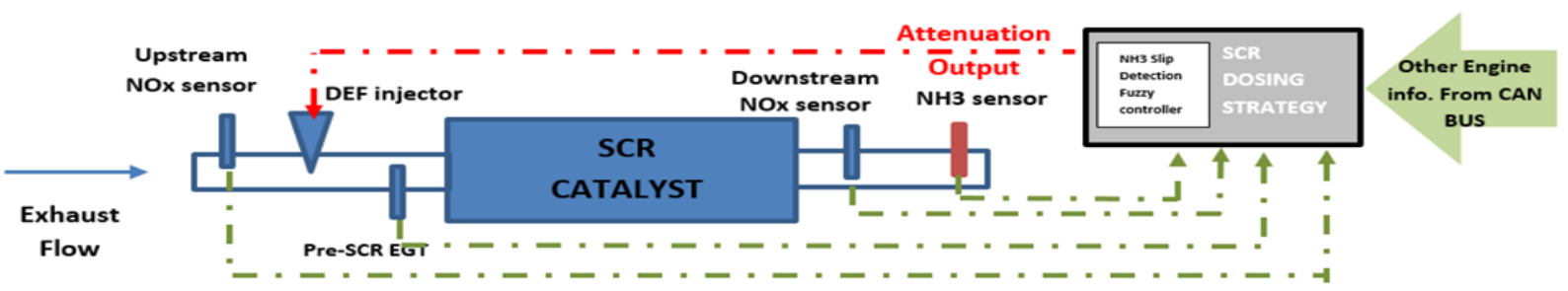

Figure 2 SCR control system components, including pre-SCR exhaust temperature sensor, upstream and downstream NOx sensor, NH3 sensor (optional), DEF injector and SCR dosing control unit 

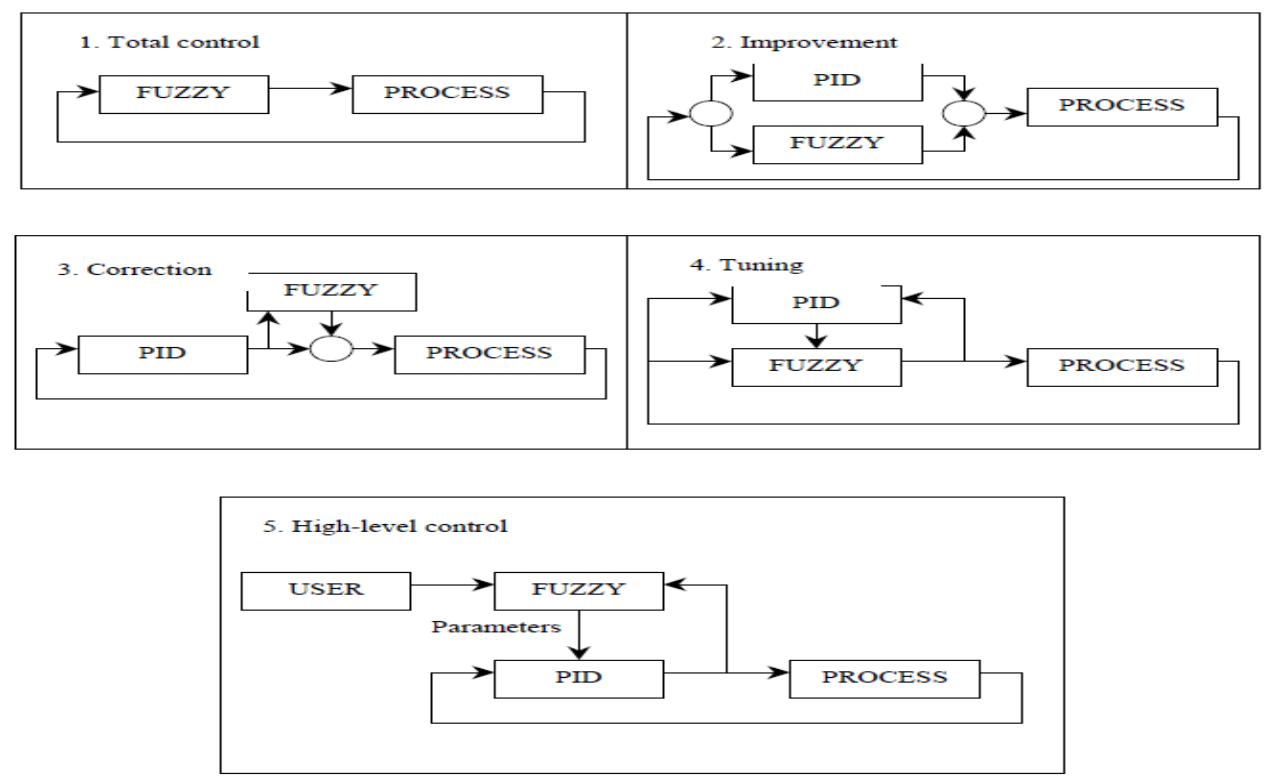

Figure 3 Roles of fuzzy logic in process control [3]

\section{Introducing fuzzy controller}

Compared with conventional control methods, fuzzy control has its advantage in dealing with problems with large uncertainties or when the system involves interpretation from linguistics inputs which adds the complexity to system itself. As mentioned in [10] fuzzy controller is typically useful when dealing with the following applications: system is too complex to be fully understood or modeled; the system is ambiguously specified; system equipped with unreliable or imprecise measurement with sensors.

The SCR system involves multiple factors, such as: 1) varied engine operating conditions; 2) deteriorating performance due to aging of SCR catalyst; 3) measurement errors from system sensors, like EGT sensor, NOx sensors; 4) degradation of DEF solution; 5) DEF decomposition loss; 6) difference between requested and actual delivered DEF amount through urea injector. In addition, with the multiple chemical reactions correlated, the system itself is very complex to be fully modelled or to be capable of producing reliable prediction under all circumstances. Although, the most popular approach in the industry still relies on the physics-chemical model to predict $\mathrm{NH} 3$ and NOx escaping from the SCR bricks as well as NH3 loading capability in real time, it still has its limitation particularly when dealing with transient conditions. Meanwhile, NOx sensors are known to be cross-sensitive to $\mathrm{NH} 3$ gaseous in the exhausts; when the SCR system subject to transient conditions after fully loaded with
$\mathrm{NH} 3$ in case of vehicle acceleration, NH3 is most likely to escape from the brick; the downstream NOx sensor then interprets it as a poor NOx reduction rather than $\mathrm{NH} 3$ slip due to its cross sensitivity to NH3. As a result, the feedback control will increase the DEF dosing flow rate leading to even more severe NH3 slip so on and so forth. With the purpose to achieve NOx reduction target while still keeping the $\mathrm{NH} 3$ slip under standard limits over the entire testing cycles, the control system is required to be capable of capturing the potential $\mathrm{NH} 3$ slip event and also differentiate that from poor NOx reduction. Once NH3 slip is confirmed, the control attenuation shall start to reduce the DEF dosing flow rate. The system control and fuzzy control subsystem are shown in Figure 3. Among all the listed control structure, the correct relation will be selected as the attenuation schematic.

\section{A. Input selection}

Before we select the proper variables as inputs to FLC, we need to understand that SCR catalysts tend to store more $\mathrm{NH} 3$ under lower exhaust temperature; the more NH3 stored on the brick, the better the NOx conversion efficiency is. Hence, the NOx conversion efficiency can be interpreted as a function of exhaust temperature and ammonia storage amount. As shown in Figure 4, for a well-calibrated SCR control system, the NH3 slip was still often observed during the World harmonized transient cycle (WHTC). WHTC is the most prevalent heavy-duty certification procedure for engine exhaust emissions. It consists of 
1800s duration, created covering driving conditions in the EU, USA, Japan and Australia. As indicated in the plotting, the temperature profile will go through a transient ramp up, during which the nearly fully loaded SCR will lose certain space for NH3 storage; as a result, the redundant $\mathrm{NH} 3$ will be vacuumed from the catalyst. In order to capture NH3 slip under this pattern, the gradient of Pre-SCR temperature, the gradient of SCR storage capacity as well as the measured NOx conversion efficiency are selected as inputs for 'slip suspect' FLC. In addition, a second FLC is introduced afterwards, taking the output from the first FLC and then generate the final output as the confidence degree of NH3 slip determination.
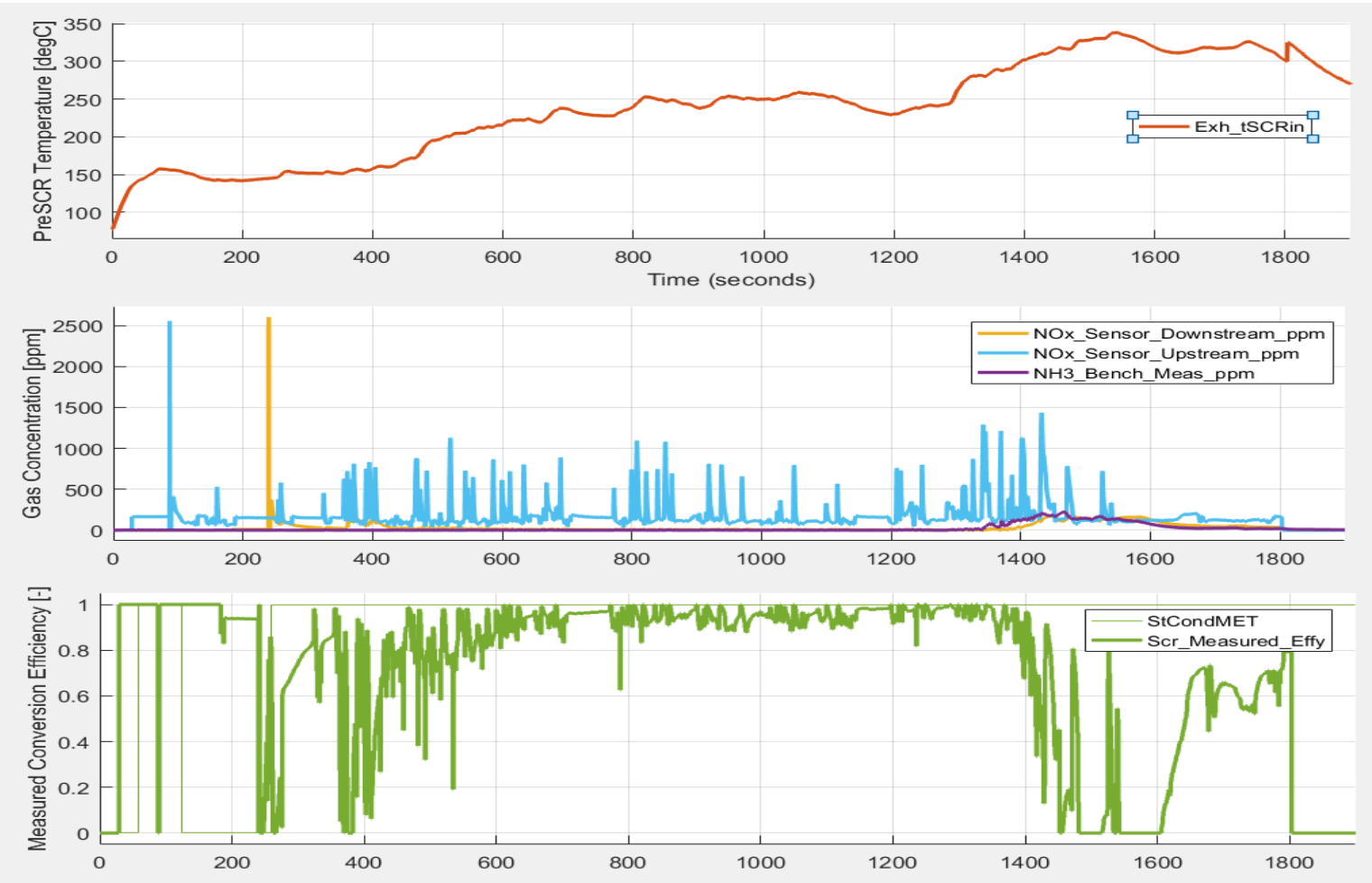

Figure 4 Sampled WHTC data with illustrated NH3 slip at the end of emissions cycle. Top graph: Pre-SCR temperature signal; Middle graph: NOx sensor signals and NH3 bench measurement; Bottom graph: calculated NOx conversion efficiency based on Knox sensors

\section{B. Membership function and rule base selection}

According to data processing results based on the large amount of recordings collected from test cell. The selected three inputs are very typical indication of NH3 slip detection. As shown in Figure 5, they are named as 'dTemp', 'dnh3Capacity' and 'rEstEffy' representing temperature gradient, gradient of SCR storage capacity and the measured NOx conversion efficiency, respectively. 'StSuspect' as the output, indicates the likelihood of an event being suspected as a NH3 slip. The membership function properties including range, membership name and type selected for each function are listed in Table 1. Mamdani type is chosen for this FIS. Figure 6 shows the surface viewer.
27 rules are used here, the decision making logic is listed in Table 2, which are all based on data analysis and experiences with the system.

Centroid method is selected for defuzzification. In order to obtain the confidence degree of truly existing NH3 slip, the output from 'NH3 Slip_Detection' FLC with another variable 'cncNOxAccum' together, the gradient of the downstream NOx sensor after NH3 slip being suspected, are taken as inputs for a second FLC 'NH3_Slip_Determination'. The range of the second input 'cncNOxAccum' is $[0,20]$; three membership functions: Low, Medium and High are selected for both 'cncNOxAccum' and output 'stDetermination'; as the most practical method, the centroid is selected for defuzzification process. 
Adnan Shaout et al.

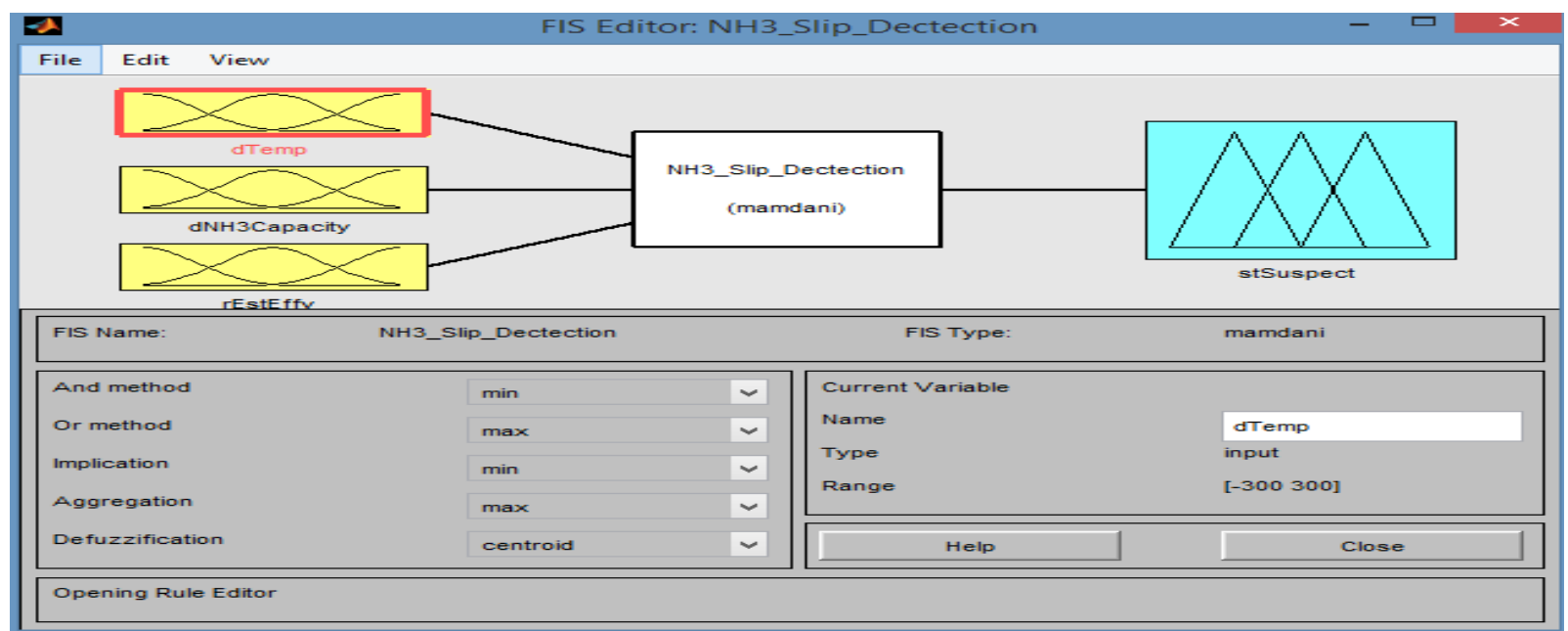

Figure 5 FIS Editor of 'NH3_slip_detection' FLC

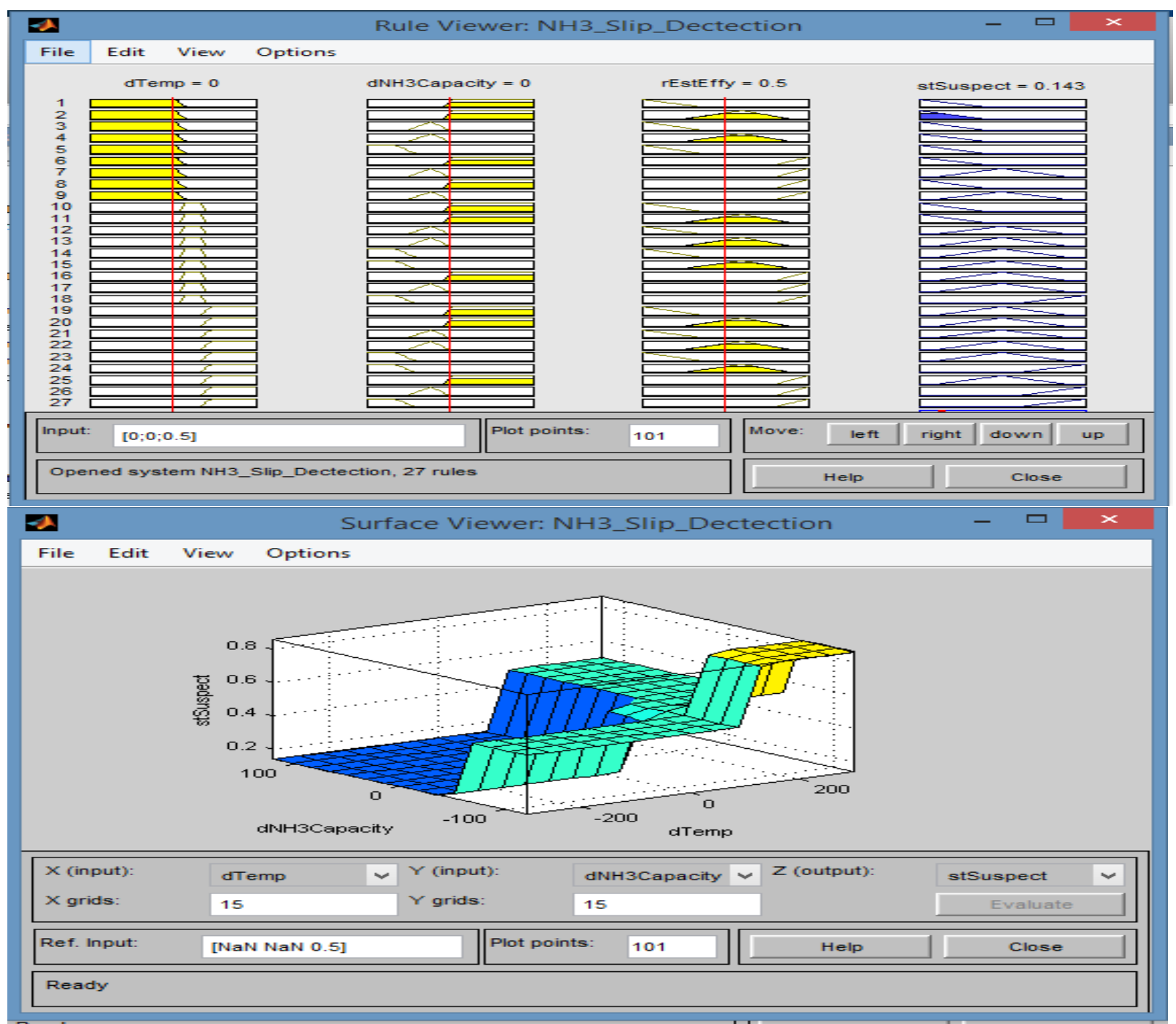

Figure 6 Top figure: rule viewer of 'NH3_slip_detection.fis'; bottom figure: surface viewer of 'NH3_slip_detection.fis' 
Table 1 Membership function properties of Nh3_slip_detection' FLC

\begin{tabular}{|c|c|c|c|c|}
\hline & dTemp & dnh3Capacity & rEstEffy & stSuspect \\
\hline Range & {$\left[\begin{array}{lll}-300 & 300]\end{array}\right.$} & {$\left[\begin{array}{lll}-120 & 120\end{array}\right]$} & {$\left[\begin{array}{ll}0 & 1\end{array}\right]$} & {$\left[\begin{array}{ll}0 & 1\end{array}\right]$} \\
\hline $\begin{array}{l}\text { Membership } \\
\text { Function 1\# }\end{array}$ & $\mathrm{L}(\mathrm{zmf})$ & $\mathrm{H}(\mathrm{zmf})$ & $\mathrm{L}($ trimf $)$ & $\mathrm{L}($ trimf $)$ \\
\hline $\begin{array}{l}\text { Membership } \\
\text { Function 2\# }\end{array}$ & $\mathrm{M}$ (gbellmf) & $\mathrm{M}($ trimf $)$ & $\mathrm{M}($ trimf $)$ & $\mathrm{M}($ trimf $)$ \\
\hline $\begin{array}{l}\text { Membership } \\
\text { Function 3\# }\end{array}$ & $\mathrm{H}(\mathrm{smf})$ & $\mathrm{L}($ trapmf) & $\mathrm{H}(\mathrm{smf})$ & $\mathrm{H}($ trimf $)$ \\
\hline
\end{tabular}

Table 2 Logic function of nh3 slip detection' FLC

\begin{tabular}{llll}
\hline dTemp & dnh3Capacity & rEstEffy & stSuspect \\
\hline Low & Low & Low & Low \\
Low & Low & Medium & Low \\
Low & Medium & Low & Low \\
Low & Medium & Medium & Low \\
Low & High & Low & Low \\
Low & High & Medium & Medium \\
Low & Low & High & Low \\
Low & Medium & High & Medium \\
Low & High & High & Medium \\
Medium & Low & Low & Low \\
Medium & Low & Medium & Low \\
Medium & Medium & Low & Medium \\
Medium & Medium & Medium & Medium \\
Medium & High & Low & Medium \\
Medium & High & Medium & Medium \\
Medium & Low & High & Medium \\
Medium & Medium & High & Medium \\
Medium & High & High & Medium \\
High & Low & Low & Medium \\
High & Low & Medium & Medium \\
High & Medium & Low & Medium \\
High & Medium & Medium & Medium \\
High & High & Low & Medium \\
High & High & Medium & High \\
High & Low & High & Medium \\
High & Medium & High & Medium \\
High & High & High & High \\
Low & Low & Low & Low \\
Low & Low & Medium & Low \\
Low & Medium & Low & Low \\
\hline & & & \\
\hline
\end{tabular}

\section{Integration into Simulink}

Both FLC and the conventional timer-based algorithm is then incorporated into Simulink for performance validation as well as a comparison between the two methods. Although the algorithm was generated mainly to capture NH3 slip under transient event, we would still like to see its performance under steady state which is the most commonly encountered situations in real-world driving. Hence, both World harmonized stationary cycle (WHSC) and WHTC profile are used for performance testing. Figure 7 illustrates the model view of the Simulink implementation from top level. Subsystems implemented in order from left to right, from top to bottom are 'Inputs', 'ASD Signal Processing', 'Timer-Based', 'FLC' with a scope viewer inserted for visually performance checking. Among them, 'Inputs' is the interface, importing recorded data from Matlab workspace into Simulink; 'ASD Signal Processing' takes original inputs and generate necessary gradient signals as stated in the previous section for slip detection. Subsystems as 'FLC' and 'Time-based' then take processed variables for decision making. The detailed implementation under timer-based subsystem and FLC subsystem are shown in Figure 8 and 9, respectively.

As indicated in Figure 7, the timer-based algorithm heavily relies on the calibration which is more of a crisp dataset based on experiences and analysis of experimental data. With that, the FLC algorithm allows more tolerance in system inputs typically when they are not highly reliable or very noisy.

\section{Simulation results}

Both WHTC and WHSC profiles are used for validation. Figure 8 and 9 are the simulation results. The bottom plotting in Figure 8 demonstrates results from new proposed FLC and the timer-based logic.

The bench measured NH3 slip and downstream NOx signal are plotted out in the bottom plotting window, in color of blue and red, respectively. In the middle, the confidence degree of a truly existing NH3 slip, plotted in blue is shown. The output from the conventional method, plotted in red, is a logic status with '1' representing 'Captured','0' for 'No Slip Captured'. Both methods managed to capture NH3 slip within the required time range (less than 5 minutes from where NH3 slip number greater than 30 ppm).

Based on the simulation results, the FLC shows its great advantage over conventional method in terms of faster NH3 slip prediction by approximately 200 seconds for WHSC, if 'stDetermination' $>0.8$ is considered as a threshold of NH3 slip. Similar results can be seen from WHTC simulation in Figure 9 
Adnan Shaout et al.

where the FLC has faster response by 80 seconds compared with conventional methods.

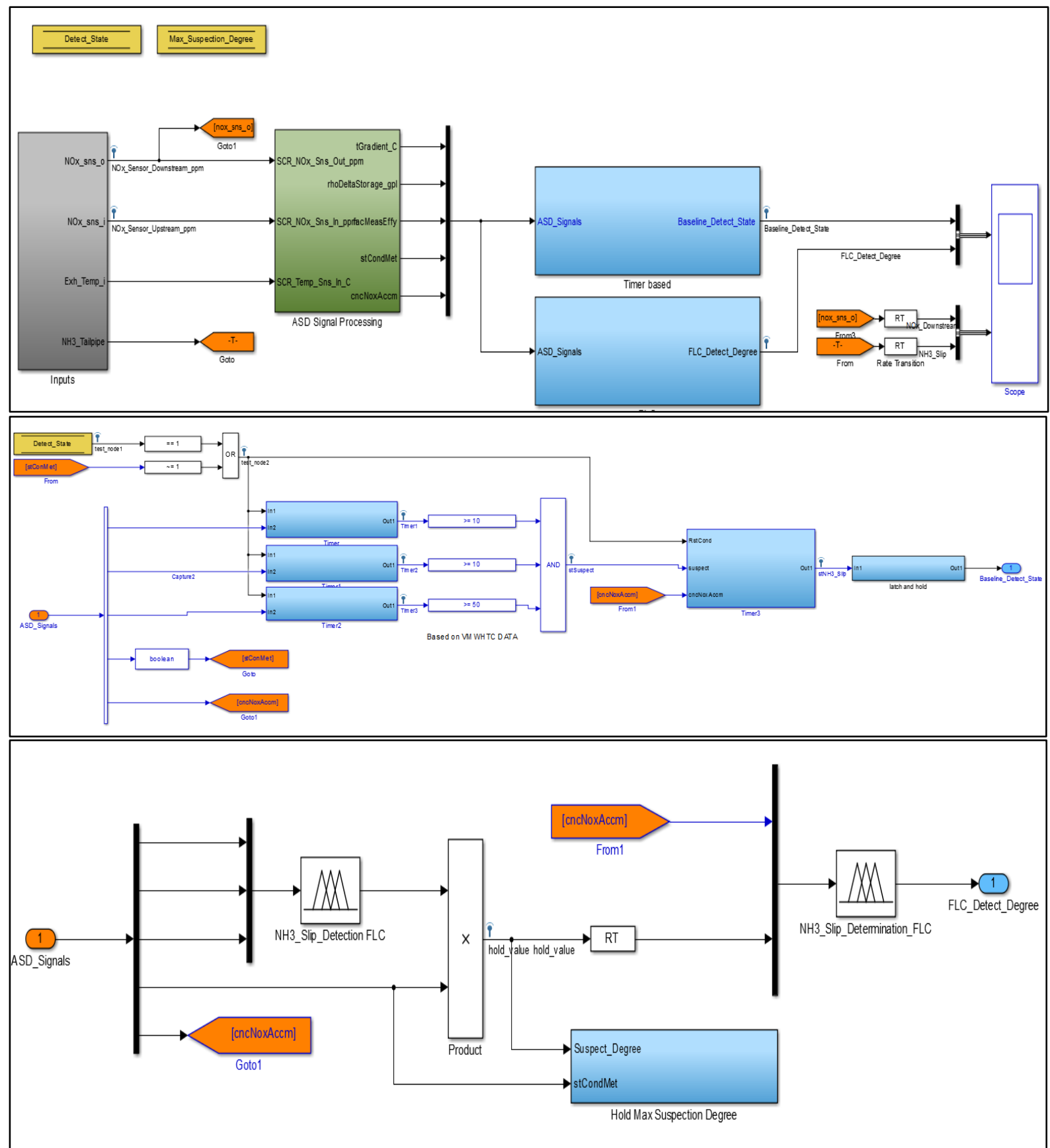

Figure 7 Model view of Simulink implementation. From top to bottom: top level overview of 'Nh3_slip_detection'; conventional timer-based subsystem; FLC subsystem

Once NH3 slip is captured, NH3 slip attenuation shall be 'switched on', which is currently a look-up table calibrated using the emissions data with the aim of preventing over dosing of DEF. As relatively low reliability comes out of the SCR plant model, we 100 normally verify the feedback control strategy on engine bench. This is the part of work left for future effort since the engine bench is currently not available. 


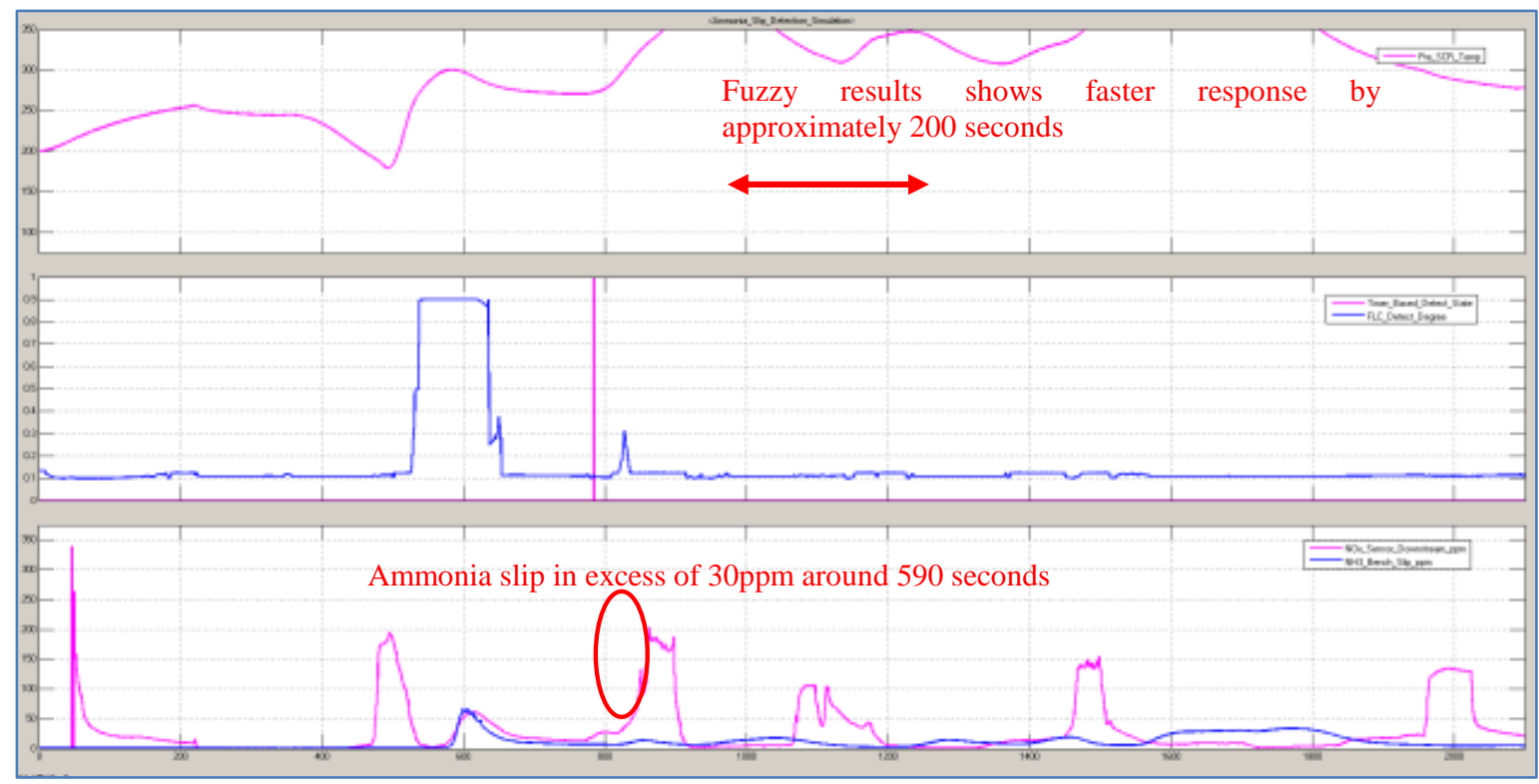

Figure 8 WHSC simulation results

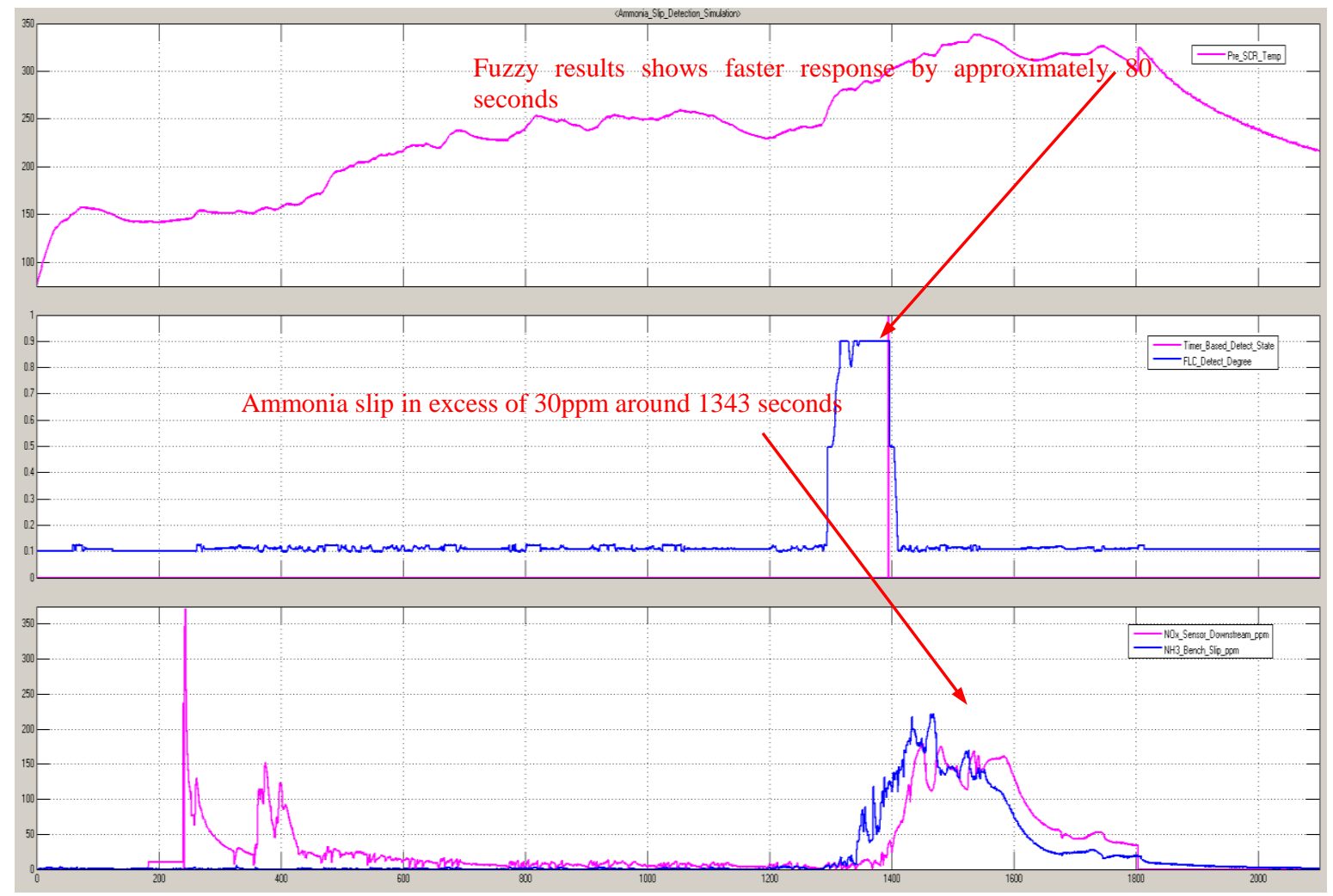

Figure 9 WHTC simulation results

\section{Conclusion}

A fuzzy control method using fuzzy inference system for NH3 slip detection was proposed in this paper. Two fuzzy FLC was chained together for determining 101 of the NH3 slip event. Different from most state-ofart NH3 slip detection approaches which still more or less rely on the reliability of the plant model. As a comparison, a conventional timer-based slip 
detection algorithm was implemented in Matlab/Simulink along with the proposed FLC. The simulation results from the most representative emission cycles for heavy-duty diesel engines, known as WHTC and WHSC, have shown that the proposed method using FLC outperformed the conventional method. The new proposed FLC have shown faster detection with higher tolerance with noisy system inputs. Moreover, rather than giving a crisp output, the FLC continuously predicted the confidence degree of NH3 slip determination, which allowed for further engineering judgments in the final decision making. Future work would include researching the attenuation strategy which has not been covered in this paper as it requires access to either hardware-inloop (HIL) system or engine bench for validation. The output from the proposed fuzzy controller system is likely to be used as the basis for DEF dosing attenuation, which is also worthy researching in the future.

\section{Acknowledgment}

None.

\section{Conflicts of interest}

The authors have no conflicts of interest to declare.

\section{References}

[1] Diesel engine emissions [MAK Value Documentation, 2008]. The MAK Collection for Occupational Health and Safety. 1-60. 2015.

[2] Technology page on SUN-A Corporation website. http://www.sun-

awks.co.jp/technology_en/environment/. Accessed 14 February 2017.

[3] Lintunen T. Advanced control methods for reducing nitrogen oxides in a fluidized bed boiler. Lappeenranta University of Technology. 2001.

[4] Singh N, Charintranond PB, Miller MJ. Ammonia slip detection. United States Patent Application US 13/943,474. 2013.

[5] Zayan NM. SCR ammonia slip detection. United States Patent US 8,607,548. 2013.

[6] Zhang H, Wang J, Wang YY. Optimal dosing and sizing optimization for a ground-vehicle diesel-engine two-cell selective catalytic reduction system. IEEE Transactions on Vehicular Technology. 2016; 65(6):4740-51.
[7] Sakthivel R, Aravindh D, Selvaraj P, Kumar SV, Anthoni SM. Vibration control of structural systems via robust non-fragile sampled-data control scheme. Journal of the Franklin Institute. 2017; 354(3):126584.

[8] Jiao P, Li Z, Shen B, Zhang W, Kong X, Jiang R. Research of DPF regeneration with NOx-PM coupled chemical reaction. Applied Thermal Engineering. 2017; 110:737-45.

[9] Zhang H, Wang J. Adaptive sliding-mode observer design for a selective catalytic reduction system of ground-vehicle diesel engines. IEEE/ASME Transactions on Mechatronics. 2016; 21(4):2027-38.

[10] Albertos P, Sala A. Fuzzy logic controllers. Advantages and drawbacks. In VIII international congress of automatic control 1998 (pp. 833-44).

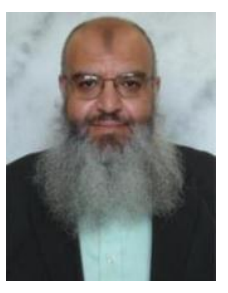

Dr. Adnan Shaout is a full professor and a Fulbright Scholar in the Computer Science Department at the Electrical and Computer Engineering Department at the University of Michigan - Dearborn. At present, he teaches courses in AI, Embedded Systems, Software Engineering, Computer Architecture, Cloud Computing, Fuzzy Logic and Engineering Applications and Computer Hardware Design. His current research is in applications of software engineering methods, cloud computing, embedded systems, fuzzy systems, real time systems and artificial intelligence. $\mathrm{He}$ has more than 34 years of experience in teaching and conducting research in the Computer Science, Electrical and Computer Engineering fields at Syracuse University and the University of Michigan - Dearborn. He has published over 210 papers in topics related to Computer Science, Electrical and Computer Engineering fields. He has obtained his B.S.c, M.S. and Ph.D. in Computer Engineering from Syracuse University, Syracuse, NY, in 1982, 1983, 1987, respectively.

Email: shaout@umich.edu

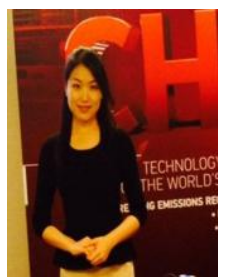

Ms. Yang Yang is a graduate student in the Department of Electrical and Computer Engineering at the University of Michigan - Dearborn. She was a Controls Engineer at Company Tenneco China R\&D Center from September 2010- September 2013. She was also a Controls Algorithm Engineer at Diesel After treatment Tenneco, Inc from September 2013 until September 2016. She is currently a Controls Engineer at Vehicle Dynamics Tenneco, Inc. since October 2016. 